\title{
EVOLUTION AND REVIEW OF BINDING MATERIALS FROM ANCIENT TO MODERN ERA
}

\author{
KUSHAL KANKARIYA ${ }^{1} \&$ Dr. VIKAS GANDHE ${ }^{2}$ \\ ${ }^{1}$ Research Scholar, Rishabh Green City, Pulgoan Chowk Durg, Chattisgarh, India \\ ${ }^{2}$ Professor, School of Architecture, I. P. S academy, Indore, Madhya Pradesh, India
}

\begin{abstract}
In construction industry, binding materials such as mortar plays a vital role from ancient to modern era. Mortar is classified as lime mortar and cement mortar. Cement and lime are main constituents for preparing the mortar. Since many years lime mix, in ancient era were added with various constituent as molasses, leaves, eggs different herbals, boiled stems of banana plants, types of oils, types of pulses etc. While in modern era, cement as a main constituent, is added with different types of admixtures as a good mortar. It was observed that the addition of herbals from 5\% - 20\% to lime increases the flexure, tensile and compressive stress from $20 \%-80 \%$. It is also observed that the life of mortar prepared in ancient era, is more as compared with the mortar prepared in modern era. The long term advantages / disadvantages of mortar in both eras were compared and dealt in detail in the present paper.

KEYWORDS: Admixtures, Ancient, Herbal, Lime, Mortar \& Modern
\end{abstract}

Received: Mar 16, 2020; Accepted: Apr 06, 2020; Published: Apr 29, 2020; Paper Id.: IJCSEIERDJUN20201

\section{INTRODUCTION}

Years together, the common construction and binding materials were used by engineers. The use of waste and recycled materials did not become popular because it had not been yielding the desired results for a longer period. Bricks, stones are bound by a paste known as mortar. It gives strength to the structure. Mortar is used to fill the irregular gaps between masonry work (either stone or brick). Lime mortar, cement mortar etc. are the different types of mortar used in construction of building.

\section{Main Function of Mortar in Construction}

- $\quad$ Binds masonry units (bricks or stone).

- $\quad$ Provide strength to the structure.

- Offers force between two structural units.

- Important medium to distribute the force uniformly throughout the structure.

- Provide resistance against rain and other external forces.

\section{Properties and Quality of Good Mortar}

\section{Workability}

It is the most important property of mortar. Some indications of workability are: It can be spread easily with the help of trowel. It also supports the weight of masonry unit. 


\section{Strength}

To eliminate moisture, drying action was taken place in mud mortar and non- hydraulic lime mortar so that it gains strength. In the case of hydraulic lime mortar, it gains strength due to hydration.

\section{Water Retention}

A mortar should always have adequate amount of water content. It is difficult to get harden, if water gets separated from mix, it also reduces the strength of mortar. Without sufficient water, it cannot develop strong bond with stone /brick.

\section{Adhesive}

Mortar should have sufficient adhesive property, so it can develop the strong bond with masonry units.

\section{Durability}

It refers to the ability of structure to substantially maintain its original appearance and strength for many years. To get the satisfactory result of a masonry structure throughout its life, durability of mortar plays a vital role.

\section{No Cracks}

Bonding property plays an important role to avoid cracks in masonry. It is caused due to shrinkage and thermal movement of units. If mortar makes a good bond with units, it is observed that movement of units due to shrinkage is evenly distributed and provides strength to masonry

\section{Ancient Era}

Mortars are the binding agents, extensively used for binding masonry since ancient times. The first green versatile building material is Lime. As compared to cement, the traditional lime mortar had greater durability, but less strong as compared to cement. In ancient times, there was lack of stones and had abundance quantity of clay, the first mortar were made of mud and clay. Babylonians were constructing the structures using lime mortar. Harappa city was found to be using brick masonry and a gypsum mortar as a binding material. Gypsum mortar is also known as plaster of paris, which was used in Egyptians pyramids and other structures. Low firing temperature was required to make gypsum. Gypsum was added to make lime mortar. As compared to traditional mortars, this mortar sets up faster. Gypsum mortar was not durable in damp conditions. Lime mortar was used to bound lime stone blocks in ancient era.

Indian subcontinent in Mohenjo-Daro city was constructed with gypsum mortar. This mortar was light grey in colour and contains high percentage of lime. It also contains calcium carbonate. Well, drains, and such other exterior components of buildings was constructed using this mortar. Bitumen mortar was also used in Great bath and in some large buildings. The Harappan people at Lothal were using mud mortar as binding material in the construction of residential building. The use of lime mortar in the Harappan city was limited to the construction of drains, baths and other such locations. In Great Bath building in Harappa, the cement was used to make it as leak proof (Fig-1, Great bath building ). The bitumen was used more than cement in the Harappan structures. The proportion of different materials used in the making of cement are as follows:-

Gypsum $43.75 \%$, Carbonate of lime $13.78 \%$, Sand $40.00 \%$, Alkaline Salts $2.47 \%$ 


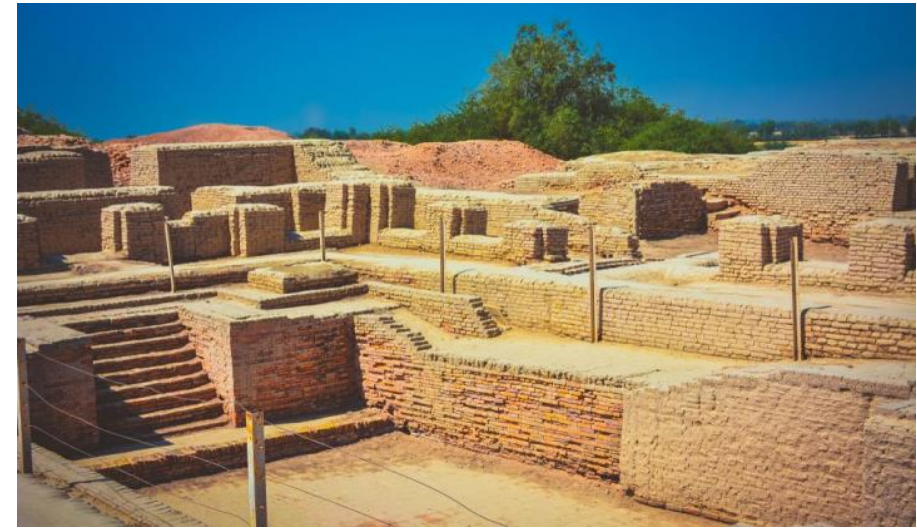

Figure 1: Great Bath Building.

In ancient era, building with concrete and mortar were used in Greece. When excavated and found an underground aqueduct. Twelve (12) mm thick pozzolanic mortar was used as a coating of reservoir. This is around 500 BCE. It is type of lime base mortar but is added with volcanic ash which allows the mortar to be hardened under water. Such type of lime is also known as hydraulic cement. Romans invented a mortar not using pozzolana but used terra-cotta, which includes aluminum oxide and silicon oxide together in this mix, which was weak as compared to pozzolonic mortar. But, an inorganic /organic composite silky rice mortar had found more strength and greater resisting strength of water as compared to lime mortar.

\section{Structural Mortar}

- Lime is added with Pozzolana to make Hydraulic mortar. This is important for construction of harbours, water proofing of floors and roofs. It had a greater strength and quicker curing time.

- Lime is added with volcanic ash, which is effective for making lime mortar that sets under water.

\section{Water Proof Lime Mortar}

To make water proof lime mortar, different ingredients were mixed in different proportions. Slaked lime is mixed with different constituents with following ratio, slaked lime with ghee 1:0.03, slaked lime with coconut water 1:0.04, slaked lime with black gram paste 1:0.05, slaked lime with extract of bark 1:0.06, slaked lime with milk 1:0.07, slaked lime with curd 1:0.08.

\section{Admixtures}

It is an ingredient of mortar, added to modify the property of mortar. It can be added before or while mixing. Paper deals with three types of admixtures. Mineral and organic admixtures were used in ancient era. Chemical admixtures were used in modern era.

There are three types of admixtures:

- Chemical admixtures (used in modern era)

○ Mineral admixtures

- Organic admixtures 


\section{Mineral Admixtures}

In ancient era, mineral admixtures were naturally available. These were inorganic / organic in nature. Rice husk ash was used as inorganic mineral admixtures.

\section{Organic Admixtures}

Organic admixtures were only used in traditional lime mortar. These are found in the form of plants and animals derivatives.

Types of herbals used: In china, sticky rice was used as admixture. It plays a vital role to enhance the properties of lime water, such as consolidation. To improve the properties of water, absorption and salt resistance sticky rice was used. It gives excellent performance.

Different herbals were used in mud. Medicinal herbs are used for plastering. Mixture of gypsum and ash was identified as the mortar used in Indo-Islamic architecture. Following admixtures were used to modify the properties of lime mortar.

Table 1: Properties of Mineral Admixtures

\begin{tabular}{|c|l|l|}
\hline Sl. No & \multicolumn{1}{|c|}{ Herbs } & \multicolumn{1}{c|}{ Properties } \\
\hline 1. & Curd & Soft finishing \\
\hline 2. & Pulses & Plastering \\
\hline 3. & Jute fiber & Good bond \\
\hline 4. & Gums & Decrease reaction \\
\hline 5. & Sugar & Binding agent \\
\hline 6. & Straw & Sugar reducer \\
\hline 7. & Cactus extract & Increase plasticity \\
\hline
\end{tabular}

Lime mortar 1:2 with 15 days of fermentation with traditional herbs, increases flexure, tension and compressive strength. Mixing 5\% of herbs, increases 1.6 x strength in lime mortar as compared with normal lime mortar, similarly the compressive strength increases by $2.5 \mathrm{x}$ more than the normal lime mortar. The same results are shown in a tabular form (Table 2). This act of mixing of herbals increases the density of lime mortar. Generally $14 \mathrm{kn} / \mathrm{m}^{3}$ is considered as the density of lime mortar. When $5 \%$ of herbal is mixed with lime, density of lime mortar increases to $17.7 \mathrm{kn} / \mathrm{m}^{3}$. The density of lime mortar further increases to $25.8 \%$ when $20 \%$ of herbal is added to normal lime mortar.

Table 2: Comparison of Structural Properties of Traditional Binders

\begin{tabular}{|c|c|c|c|c|c|c|}
\hline Type & $\begin{array}{c}\text { Flexure Strength } \\
(\text { Load) }\end{array}$ & Increase \% & $\begin{array}{c}\text { Tensile Strength } \\
\text { (load) }\end{array}$ & Increase \% & $\begin{array}{c}\text { Compressive } \\
\text { Strength (Load) }\end{array}$ & Increase \% \\
\hline Normal lime & $250 \mathrm{~N}$ & - & $466.66 \mathrm{~N}$ & - & $833.33 \mathrm{~N}$ & - \\
\hline$+5 \%$ Herbal & $400 \mathrm{~N}$ & $60 \%$ & $850 \mathrm{~N}$ & $82.14 \%$ & $1500 \mathrm{~N}$ & $80 \%$ \\
\hline$+20 \%$ Herbal & $300 \mathrm{~N}$ & $20 \%$ & $700 \mathrm{~N}$ & $50 \%$ & $1400 \mathrm{~N}$ & $32 \%$ \\
\hline
\end{tabular}

\section{Modern Era}

In the early ages, generally clay, metal, grass, wood, stones and lime etc were the chief constituents used as binding materials of mortar with different permutations and combinations. Mortars are generally inhomogeneous because these were produced manually. Because of non availability of scientific test and modern equipments, adequate/ required improvements in the quality of mortar could not be carried out in past. But now a days, different type of techniques and scientific instruments are available, hence good results are achieved in modern era. 
The use of modern mortar are giving satisfactory results. The use of different chemicals and admixtures not only improves the workability of structure, but also gives the adequate improved results. It also resists the attack from salts and sulphates presents in a soil and sea water. In recent years, light weight concrete, polymer concrete and different types of mortar are commonly used as per the modern requirements.

Types of Mortars used in modern era are categorically expressed below:

\section{Cement Mortar (Aerated)}

To increase the plasticity and workability of cement, mortar air entering agent is used. It is used for repairing of large scale tunnels and to stabilize slips in earthwork.

\section{Heavy Mortar}

The bulk density of heavy mortar is more than $15 \mathrm{Kn} / \mathrm{m}^{3}$. In this mortar, fine aggregate of heavy quartzes is used.

\section{Light Weight Mortar}

The bulk density of Light weight mortar is less than $15 \mathrm{Kn} / \mathrm{m}^{3}$. For the preparation of Light weight mortar, following ingredients are used: sand, saw dust, rice husk, jute fibers etc. For sand proof and heat proof construction, cinder mortar is used.

\section{Mortar}

It is a mortar, which has strength more than $17.2 \mathrm{~N} / \mathrm{mm}^{2}$. For exterior masonry work, this type of mortar is used. For the construction of load bearing walls, retaining walls, this type of mortar is used, as it has higher strength.

\section{S Mortar}

It is a mortar, which has strength more than $12.4 \mathrm{~N} / \mathrm{mm}^{2}$ but less than $17.2 \mathrm{~N} / \mathrm{mm}^{2}$. The strength of this mortar is medium. For the construction of shallow retaining wall, this type of mortar is used. As it has medium strength, it is used where the loading is moderate.

\section{N Mortar}

It is a mortar, which has strength more than $5.2 \mathrm{~N} / \mathrm{mm}^{2}$ but less than $12.4 \mathrm{~N} / \mathrm{mm}^{2}$. The strength of $\mathrm{N}$ type mortar is medium. Exterior load bearing walls were constructed with this type of mortar. It is used where loading is normal.

\section{O Mortar}

It is a mortar, which had strength more than $2.5 \mathrm{~N} / \mathrm{mm}^{2}$. The strength of this mortar is low, hence it is used for the construction of non-load bearing walls. This type of mortar is often used for repairing works.

\section{Fire Resistant Mortar}

Aluminous cement is mixed with powder of fire bricks to make Fire resistant mortar. This mortar is used as fire proof mortar. Perlite or Vermiculite is the aggregate which is mixed with fire resistance mortar.

\section{Sound Absorbing Mortar}

Sound absorbing mortar is mixture of cement, lime and gypsum. Fine aggregate such as pumice, cinders are mixed with sound absorbing mortar. For the construction of recording studios, theaters etc. this mortar is used as it reduces the noise level. It forms a layer which acts as a barrier to sound. 


\section{Chemical Resistant Mortar}

Chemical resistant mortar is the mortar which helps structure to resist from chemical attacks. There are different type of chemical resistant mortars which are made according to the required site conditions. These type of mortars are made to resist attack from chemical or group of chemicals. Some chemical mortars are made to resist acidic attacks and some are made to resist the attack of alkalines.

\section{X-ray Shielding Mortar}

$\mathrm{X}$-ray shielding mortar protects structure from the effect of X-ray. The bulk density of X-ray shielding mortar is $22 \mathrm{Kn} / \mathrm{m}^{3}$. This type of mortar is prepared from the fine aggregates of heavy rocks. This mortar is used in X-ray and M. R. I rooms.

\section{Epoxy Mortar}

High viscosity epoxy resin is mixed with fine aggregate to make epoxy mortar. Large voids are filled with the help of this mortar. Strength of concrete is less than epoxy mortar. To enhance the modulus of elasticity, sand is mixed with epoxy mortar.

These types of mortars are used with different types of admixtures.

Chemical admixtures are the admixtures used to enhance the properties of mortar. Manufacturing of chemical admixtures badly effects the environment. Calcium chloride, synthetic derivatives etc are the chemicals used in modern days to alter the properties of mortar. Fly ash, silica fume etc are some of the mineral admixtures that are used in modern era.

These are the admixtures that are used to alter the properties of mortar as per the site conditions

The instruments and scientific methods to test the properties of mortars and its constituents available now a days are listed below:

\section{Thermo Gravimeter}

The effect of change of temperature on a given soil sample is observed on this instrument. This instrument expresses the change of property of soil due to variation in temperature. Change of soil property includes absorption, adsorption, chemical changes etc. It also indicates the highest temperature at which the soil sample degrades. These tests plays a vital role in deciding the depth of foundation.

\section{$\mathrm{X}$ ray Diffractometer}

This scientific instrument is useful to analyze the structure of soil sample. The beam of $\mathrm{x}$-ray passes through the sample of soil. It clearly gives the scattered pattern of soil, due to effect of x-ray. The flexibility of soil sample can be seen graphically. Engineers are getting adequate information before deciding the depth of foundation for any structure.

\section{X ray Fluorescence Analysis}

This apparatus is used to investgate the properties of building material such as ceramic, glass, metals etc. For chemical analysis of soil, high frequency x-ray / gamma rays are passed through the soil sample. Results thus obtained are useful for field engineers. 


\section{Capillary Water Absorption Coefficient}

It is used to determine water absorption coefficient of a porous building material. It is a test for measuring the water absorption capacity of mortars. Water absorption coefficient of mortar has the positive impact as the time of curing increases.

\section{Calcimetry}

It is a method used to determine total carbonate content as well as the amount of limestone and dolomite in a sample. In this method, rate of response of diluted hydrochloric acid on rock samples is measured. Quick reaction indicates the amount of calcite and the slower reaction indicates the amount of dolomite.

\section{Sieve Analysis of Non Carbonate Aggregates}

In every civil engineer laboratory, sieve analysis apparatus is available to know the gradation of soil. These apparatus comprising of number of sieves of different diameter, plays one over the other. The soil sample is placed on top sieve. These sieves are shaked mechanically for fixed duration. The quantum of weight of soil retained on each sieve, is measure to finalize the gradation of soil.

The results thus obtained to improve the quality of mortar by various admixtures and test equipments gives better result as compared to ancient era mortars

\section{CONCLUSIONS}

- Mortars play a vital role in construction industry.

- Lime and cement are the most important constituents since ancient to modern era.

- Cement is used with different admixtures to increase the tensile, flexure and compressive stress.

- Lime is used with different herbals to increase its strength.

- Life of cement is limited to $60-80$ years.

- Life of lime can last for hundreds and thousands of years.

- Lime with $5 \%$ of herbal, increase the flexure, tensile and compressive strength by $60 \%, 82.14 \%$ and $80 \%$ respectively.

- Lime with $20 \%$ of herbal, increase the flexure, tensile and compressive strength by $20 \%, 50 \%$ and $32 \%$ respectively.

- In modern era, chemical admixtures are used to enhance the property of mortar.

- Local materials in lime is used as mortar like glue, straw, jute fiber etc which increases the bond strength, reduces the cracks and gives better bonding respectively.

- Various scientific instruments and checks are available now a days to check and improve the quality of mortar.

\section{REFERENCES}

1. Middendorf B; Knofel D ; "Characterization of historic mortars from buildings in Germany and Netherlands. In Baer NS, Fitz-s, Livinstong R(ed) ; Conservation of historic brick structures, Donhead publications 1992.

2. Awais Farooqi, "A Green Strategy Towards the Miscibility Studies of Styrofoam in Organic and Inorganic Solvents by Using Materials Modelling and Simulation Method”, Journal of General Engineering and Technology (JGET), Vol. 1, Issue 1, pp. $11-18$ 
3. J. P Adam ; A. Methews, " Roman building material and techniques " B. T. Batsford Ltd, London, 1994.

4. Nikita Sharma \& B. Jena, "Behaviour of Flyash Brick Masonry Columns”, International Journal of Civil Engineering (IJCE), Vol. 6, Issue 1, pp. 9-14

5. Aslan Ozkaya ; " Ancient building technology materials, Part-1 ; Text ; Brill ; Leiden ;Boston 2005.

6. Falah Mustafa Al- Saraireh \& Yuri Svinoroev, “Assessment of Casting Binding Materials Based on Modified Technical Lignosulfonates", IJMPERD, Vol. 10, Issue 2, pp. 335-346

7. Papayiami, V. Pachta, K. Iliadous, A. " A data base system for managing information conserving historical mortars " International conference of virtual systems and multimedia (VSMM 2008) Limassol, Cyprus,2008.

8. Baqir Abdul Redha Mubder, Anupam Rawat \& Y K Bind, "Influence of Soil and Framed Building on Intersections Using Soil Structure Interaction Analysis", International Journal of Civil, Structural, Environmental and Infrastructure Engineering Research and Development (IJCSEIERD), Vol. 4, Issue 6, pp. 1-10

9. V. Pachta ; "Study of technological evolution of mortars " Ph.D Thesis, Department of civil Engineering, Aristotle University of Thessaloniki, 2011. 